\title{
TED Talks: An Approach for Activating the World Knowledge Schema of EFL Writers
}

\author{
Dr. Grasiella K. Harb \\ Rafik Hariri University \\ Lebanon
}

\begin{abstract}
The lack of reading culture among our youth today, especially in the Arab world, has greatly limited their ideas and affected the quality of their writing. Due to their underdeveloped world-knowledge schema, they lack creativity, struggle with the brainstorming step or even skip it, and, consequently, produce essays that lack sufficient content and maturity of ideas. Hence, not only is activation of prior knowledge required but also the amount of activation is to be considered. Accordingly, the purpose of the study was to investigate the utility of short Ted Talk videos as a motivating tool that activates enough prior knowledge within a short time. The participants were 21 Lebanese undergraduates in the sophomore writing class. A mixed-method design was adopted. Data analysis revealed the effectiveness of the approach in helping students overcome the challenge of brainstorming and outlining, expand their content, show deep thinking, and feel more confident about writing.
\end{abstract}

Keywords: Ted Talk video, EFL writing, Content Schema, Prior Knowledge Activation, Brainstorming

\section{Introduction}

"If kids are avoiding eye contact, they are avoiding books even more,"

(David Denby, The New Yorker, 2016)

With the continuous attachment to the screen, today's young generation is reading more words than before. However, so many of them are reading fewer books and more scraps like excerpts, parts of magazines or articles, and some pieces of information from different sites. The continuous stimulation of internet is disrupting them from acquiring knowledge properly inside and outside their classes. They have stopped reading seriously unless it is something related to their major or exam. So the question that arises here is the following: Is today's generation reading seriously anymore?

Reading for pleasure has declined among our learners, with their continuous involvement with high-tech gadgets. The type of reading that provides quality pleasure and enhances their thinking and imagination is not on their top list anymore, hence the deterioration of their knowledge and language skills. Because of lack of creativity and rich knowledge, students tend more than before to plagiarize their assignments and overlook their language and style errors. They tend to use cyber slang in their formal writing such as shortcuts, alternative words, symbols, and abbreviations used in online-chatting mediums.

The lack of reading culture among our youth nowadays has become an issue of concern, especially in the Arab world.When it comes to the decline of reading culture among the young Arabs, part of the problem is pertained to technology invasion. Nevertheless, the other part is because "young Arabs are grappling with sectarian and political labels forced upon them" (Al-Oraibi, 2016, para.2). Over 60 million refugees are spread around the world, regularly displaced, oppressed, and executed. This is in addition to the fallout faced in the neighboring countries of Syria, Iraq, Yemen, and Libya. Instead of reading and refining their knowledge, young Arab people in conflicting areas are occupied with surviving! As for the Arabs outside the war zone, they are preoccupied with the fears of instability resulting from corruption, terrorism, and war.

We as EFL educators, inside and outside the Arab world, experience our learners' under-developed prior knowledge in the communication classes. In the writing class, the challenge starts with generating relevant, sufficient, and deep ideas for constructing a well-coherent essay. Due to their limited world-knowledge schema and lack of creativity, students struggle with the brainstorming step or even skip it. Their level of reasoning does not enable them to show deep and mature ideas, and they complain of having a blocked mind (Mghsoudi \& Haririan, 2013). 
Hence, because of their limited discourse competence (Oishi, 2015), their essays lack sufficient content and maturity of ideas. Therefore, not only is activation of prior knowledge required but also the amount of activation is to be considered.

The following study targets 21 Lebanese undergraduates in the sophomore writing class (ENGL 210 English Composition and Rhetoric). The aim was to integrate TED TALK videos in the writing process and investigate its effectiveness in motivating students and helping them activate prior knowledge within a short time. Listening to mature ideas discussed in Ted talk videos creates a motivating environment for students, eases the brainstorming and outlining process, promotes the thinking abilities of students as writers, and enhances their creativity in writing. Hence, the study suggests a new accessible approach, which is familiar, easy to use and aligns with the integration of Internet Communication Technologies (ICTs) in education. Furthermore, it responds to the demand of researchers and educators who have called for new contemporary brainstorming strategies.

\section{Literature Review}

\subsection{Creativity in Writing}

Students' creativity has been steadily targeted in education for its fundamental role in shaping learners' life (Rababah, Bin Mohamed, Jdaitawi, \& BaniMelhem, 2013). Myriad research studies suggest that developing students' creativity facilitates their learning. In EFL classes, enhancing creativity makes difference in the way students perceive things, think of ideas, and solve their problems. Also, creative thinking significantly increases students' ability of showing proficiency level on standardized tests, for they engage high critical analysis with prior knowledge and problem solving skills (Goldbers \& Bush, 2003). Nevertheless, emphasizing creativity in writing is not only to improve students' academic performance; the goal is to enhance their thinking process, teach them how to make life decisions in a creative and productive way in any life situation (Treffingeret al., 2003). In fact, creativity is one of the levels of language skills that EFL students should start developing right from the school (Ibnian, 2010). Besides, it is one of the highest level of Bloom's digital taxonomy (remembering, understanding, application as lower order skills) and (analyzing, evaluating, and creating as higher order skills).

Torrance (1995) measured creativity in writing according to four main dimensions: fluency, flexibility, originality, and elaboration. Later, he eliminated flexibility as it strongly correlates with fluency. The four dimensions are described as such:

1- Fluency: refers to the divergent thinking or the number of different ideas produced

2- Flexibility: refers to the different perspectives one produces such as producing different solutions

3- Originality: refers to how unusual the ideas produced are, including remote associations

4- Elaboration: refers to the number of details produced to expand existing details and further elaborate a response

(Rababah et al., 2013, p.25; Wu \& Chiou, 2008; Torrance, 1974)

Fluency and flexibility refer to the quantity of ideas, while originality and elaboration reflect quality writing. Unfortunately, despite the continuous efforts of EFL educators, students still show low level of creativity and writing performance (Ibnian, 2010). That is why educational research recommends further studies that connect creativity in writing with students' achievement (Rabbah et al., 2013), hence the goal of the current study.

\subsection{Importance of Activating Prior Knowledge}

A learner's prior knowledge is his/her pre-existing information of the world, taking into consideration the reading experience and varied information about the world and genre knowledge of texts. It is one of the factors that help develop students' creativity in writing. Schema is the mental map which helps a learner organize the link between the prior knowledge and the newly received one. It is divided into two main types. The Formal Schema is related to the linguistic knowledge of the language (grammar, syntax, word knowledge, or genre). The Content Schema is related to the knowledge of the subject matter, culture, and world knowledge. The following study targets the development of the learners' content schema or world knowledge, which depends on the inference of how things work in the world. A well-developed world schema is essential for undergraduates, for it prepares them to confront future situations which demands decoding, inferring, analyzing, evaluating, and discussing content (Madani, 2016; Dale, van der Es., \& Tanner, 2010). 
Schemata knowledge is activated in two ways:

1. New world knowledge is linked to an existing one. In this case, new concepts are replaced or extended.

2. In case of under-constructed/lack of existing schema, new knowledge gained builds new schemata (Dale, et al., 2010; Madani, 2016)

The role of the teachers is to create a motivating environment and provide suitable resources of knowledge to build the learners' existing schema, bridge any gaps, and develop a new knowledge about the world (Dale, et al., 2010; Madani, 2016). Dale et al. (2010) added that though activating prior knowledge might be time-consuming, it is fundamental for a successful learning process. It challenges learners to think critically and deeply about the subject matter and helps them notice the gap in their existing knowledge and understanding. However, in relation to the purpose of the following study, scarce studies have investigated the development of higher-level skills (generating inference and assessing provided material) during the knowledge activation process and the effect of this onEFL students' creativity and writing proficiency (Allen, Snow, Crossley, Jackson, \& McNamara, 2014). Most research have targeted activating vocabulary, grammar, reading, and cultural knowledge.

\subsection{Brainstorming and Prior Knowledge}

Brainstorming, created by Alex Osborn in the 1930s, is one of the effective methods of activating prior knowledge and generating ideas. It allows learners to clarify their main ideas and determine supporting details in an organized and coherent way (Oishi, 2015; Al-Khatib, 2012). The more ideas are generated, the more creativity is reflected in writing. However, in EFL writing, brainstorming is a challenging process because learners lack ideas related to a given prompt. Their limited discourse competence disables them from writing ideas related to the topic (Oishi, 2015). Hence, brainstorming strategies, which facilitate the process of linking existing knowledge with the new one, should be introduced in the writing processin order to help students write (Rao, 2007; Oishi, 2015). It is "only when students have better ideas of how to go about a writing task, they seem more positive and confident about the writing task" (Arju, 2016, p.14).

There are different types of brainstorming strategies adopted in EFL writing classes to help students activate prior knowledge such as mind mapping, answering questions, listing, clustering, previewing, free writing, debating, and other approaches. However, despite the wide adopted variety, challenges still exist. The main limitation for brainstorming is that it might not be easy for young undergraduates because of their level of reasoning that hinders them from showing enough maturity and relevance in discussing their ideas (Arju, 2016; Al-Khatib, 2012; Jameel \& Mohamood, 2017). Many learners complain that they do not feel motivated about writing because they lack enough ideas or get "blocked mind" and cannot think of something relevant, significant, and interesting to elaborate their writing and convey a meaningful message. Hence, teachers end up perplexed by their students' challenges and feel helpless in finding "efficient way to awaken students' imagination and set their minds working" (Mghsoudi \& Haririan, 2013, p. 60). Consequently, because of anxiety and the difficulty of organizing the content message, the pre-writing stage has become a neglected one by many learners (Tompkins as cited by Arju, 2016). Hence, researchers and educators have recommended contemporary approaches in EFL writing classes for emphasizing the brainstorming strategies (Nurlaila, 2013; Andrisnsyah, 2015). Accordingly, the following study recommends YouTube videos and, in particular, Ted Talks as a new motivating approach that facilitates the brainstorming process and, at the same time, aligns with the interests of the $21^{\text {st }}$ century -digital generation.

\subsection{YouTube and Ted Talks}

Writing imposes a cognitive demand on EFL learners, and recently a number of teachers and researchers added the Internet Communication Technologies (ICTs) to widen the learning opportunities of writing and add creativity to the teaching and learning process (Mayora, 2009; Bajrami \& Ismaili, 2016). In this respect, Jeffreyand Craft (2004) clarify the need for distinguishing between teaching creatively and teaching for creativity. The former highlights the teacher's implementation of effective, engaging, and motivating approaches. The latter emphasizes the teacher's integration of approaches intended to stimulate and optimize learners' creativity in terms of behavior and thinking. Hence, both concepts are interrelated.

The positive outcomes of (ICTs), such as the utilization of online forums, wikis, and blogs, have encouraged teachers to integrate other digital forms into their classes, among them: YouTube (http://www.youtube.com). 
YouTube (YT) has been widely adopted by EFL teachers who feel enthusiastic about its use due to the variety of topics the social network offers. According to Rivers "all audio visual materials have positive contributions to language learning as long as they are used at the right time, in the right place (cited by Mayora, 2009, p.3).

(YT) videos are spoken in a different variety of languages and are of different difficulty levels (Mayora, 2009; Li, Ghao, \& Zhang, 2016). Moreover, they are easily accessible from any high-tech device; their storage is retrieval, and their transportation is easy without resulting in quality loss (Godwin-Jones, 2007). Their music and audiovisual effects are entertaining and enjoyable for learners. However, (YT) potential in helping develop EFL writing hasn't been sufficiently investigated (Mayora, 2009). Their efficiency in improving the writing proficiency was described by Pino-Silva who believes that "with the rapid development of digital and electronic audiovisual media, writing is now frequently integrated with listening as well (cited by Mayora, 2009, p.3).

Cumming also explained that integrated writing entails both reading to write and listening to write tasks. However, many educators fail to provide these two features in their writing classes, where writing happens in isolation and is only limited to prompt reading and quick brainstorming (as cited by Moyora, 2009). YouTube effectiveness in writing is further explored by Styati (2016), Fleck, Beckman, Sterns and Hussey (2014), and Oddone (2011) who reported that videos help students generate and organize ideas, select appropriate word choice, and produce correct sentences. More importantly, they can be employed in a cross-curriculum writing to help low-achievers in using language appropriately in their major courses. (YT) material offers learners a great amount of background knowledge and emotional attitudes about the topic. While watching the videos, students employ their autonomy in learning. Accordingly, watching (YT) videos should not be a passive activity but should involve the four skills of language (Bajrami \& Ismaili, 2016).

The following study adopts the integration of modern (ICTs) in developing the writing proficiency of the Lebanese EFL learners by integrating Ted Talk videos in the brainstorming stage. Ted is a private, non-profit organization founded for spreading valuable ideas (Broadaway, 2012). It has become the most popular venue for sharing innovative and engaging topics that have exceeded its original three fields of Technology, Entertainment, and Design (Broadaway, 2012; Hashimoto, Fukuda, \& Okazaki, 2015; Li et al., 2016). Ted website is a valuable teaching tool. Its subtitles not only offer language support but also help students understand the conceptual content of the presentation (Broadaway, 2012). Listening to Ted Talks also activates and promotes students' critical analysis. They listen critically in order to distinguish between facts and opinions, judge the validity of the evidences, analyze the whole content and decide to what extent they agree with the speaker (Li et al., 2016). Based on their scaffolding efficiency, further studies are recommended to investigate the effect of Ted Talk videos on students' achievements other than the listening and public speaking skills (Li et al., 2016). Hence, this study adopts the researchers' recommendations. The following hypotheses guide the present study:

1- Integrating Ted Talk videos in the brainstorming stage is motivating for EFL students.

2- Ted Talk video is an efficient intervention for helping EFL students show more creativity in the content of their writing and, consequently, improve their writing quality.

\section{Methodology}

\subsection{Design}

A mixed-method study was conducted on 21 undergraduates in the English Composition and Rhetoric course (ENGL 210) in an English medium private university in Lebanon. The 3 credit course is offered in the fall and spring semester and in the summer semester throughout 8 weeks (during which this study was conducted). As part of their writing syllabus, students have to sit for a diagnostic test and write persuasive and argumentative graded essays. Writing as a process is adopted, in which students do the planning, brainstorming, drafting, editing and revising step.

\subsection{Procedure}

Before integrating the intervention, students sat for a diagnostic test, referred to as a pre-test. At a later stage, students sat for a persuasive and an argumentative writing with a three-week interval. The selection of the Ted Talks videos was based on a content that helps students inspire relevant and mature ideas and reliable evidence such as statistics and expert opinions, which are difficult to deduce from their prior schema. Also, clear language, English subtitle, and clear sound and picture were taken into consideration. 
The prompt for persuasive writing was to discuss whether the Arab world has become a better place. In 75 minutes, students had to write a 5 paragraph essay with convincing reasons and valid evidence. Before listening to a ten-minute extraction of the Ted Talkvideo https://www.ted.com/talks/steven_pinker_is_the_world _getting_better_or_worse_a_look_at_the_numbers, students were given 15 minutes to brainstorm their ideas (prebrainstorming). Then, after listening to the video, students modified their brainstorming by adding or modifying ideas with a different color. The change of color helped the researcher at a later stage to trace the change in the brainstorming stage. In the remaining 40 minutes, students had to expand their draft outline to a well-structured coherent essay. In the final step, students were given 10 extra minutes to finish their $1^{\text {st }}$ draft. However, in the future, this limitationcan be avoided by skipping the pre- brainstorming step as this was done to investigate the effectiveness of the tool.

The same procedure was applied in argumentative writing. Students had to argue whether or not homework should be given in the elementary level. A five-minute extraction from each of the following videos were played: 1) https://www.youtube.com/watch?v=d_qMpV9V9To and 2) https://www.youtube.com/watch?v=FbirNmBJyfw

\section{Data Collection and Analysis}

Students' perception of the integration of Ted Talk videos in the brainstorming stage was measured by 8Likert scale questions with 5 point response scale ranging from 1 (Strongly agree) to 5 (Strongly disagree). Later, focus group interview was conducted with 12 participants, which is an acceptable number for conducting a successful focus group interview (Stewart, Shamsadani, \& Rock, 2007). Four participants from each of the low, medium, and high-achiever category were randomly selected. The triangulation of data analysis helped enhance the concurrent validity of the study and form a holistic picture on students' experience with the intervention as recommended by Creswell (2014) and Flick (2014).

An analytic rubric was employed to grade the writing corpus (pre-test, persuasion draft 1, argumentation draft 1). The heavy weight on the 1st draft was on the content of writing. The rubric for draft 1 included the following criteria: content/creativity ( $2 \%$ fluency, $1 \%$ elaboration, $1 \%$ originality), introduction $(2 \%)$, coherence $(1 \%)$, order $(1 \%)$, conclusion $(2 \%)$. For inter-rater reliability, two expert teachers corrected the corpus (pre-writing, persuasive and argumentative writing) following the same rubric. In case of grade discrepancy, a third rater was referred to. Finally, apaired t-test was employed for statistical results.Qualitative analysis was based on deducing thematic patterns from the focus group interview. In addition, content analysis for participants' brainstorming sheet was done for more concrete and descriptive evidence.

\section{Results}

\subsection{Quantitative Findings}

The quantitative findings of the study as shown in Figure 1 (see Appendix) show the effect of the integration of Ted Talk videos on the writing performance in general and the content variable in particular. Results, displayed in Table 1, reflected a progressive development in participants' writing performance. More specifically, there wasa significant difference between the diagnostic and persuasive test and between the diagnostic and argumentation test with $(p=0<0.05)$ and $(p=0<0.05)$ respectively. However, no significant difference was indicated between the persuasion and argumentation test $(p=0.1>0.05)$, which indicates a similar effect of Ted Talks in both types of writing (Appendix, Table 1). In line with the writing performance, the grade of the content had also improved, with the highest total average on the persuasive rhetorical mode. Table 2 (see Appendix) shows that there was a significant difference between the diagnostic and the persuasive test and between the diagnostic and the argumentation test with $(p=0.03<0.05)$ and $(p=0.0<0.05)$ respectively. However, no significant difference was indicated between the persuasion and argumentation test $(p=0.2>0.05)$. Results indicate that the creativity of content was one of the predicative factors behind the writing improvement.

Findings of the questionnaire (see Appendix, Table 3) on students' perception of the integration of Ted Talk videos in the brainstorming approach revealed the following about those who strongly agreed on the helpfulness of the approach: $95 \%$ found it an enjoyable way for brainstorming, 90\% found that it motivated an interest in writing about the topic, $95 \%$ found that it eased the brainstorming and outlining process, $90 \%$ revealed that the approach reduced the difficulty level of the prompt, $79 \%$ showed that it helped in improving their writing quality, $90 \%$ found the approach helpful in reflecting mature ideas, $80 \%$ found it helpful in improving their word choice, $84 \%$ felt that the approach made them more confident about writing, and $100 \%$ recommended the approach for other writing courses. 


\subsection{Qualitative Findings}

The thematic analysis of the focus group interviews revealed six main themes related to the experience of listening to Ted Talks in the brainstorming process. These themes are: 1) Ted Talk videos are enjoyable, 2) they ease the pre-writing step, 3) they reduce writing difficulty, 4) they help produce mature ideas, 5) they increase confidence in writing, and 6) they are recommended in other writing courses. Example on every theme is listed below:

Theme 1: I enjoyed listening to native speakers talking about the world and teaching me the right accent Theme 2: Ted Talk helped me to get more engaged with the topic and helped me generate more ideas in the brainstorming

Theme 3: At first I didn't know what to write about but after listening to the video what is required from me is easier

Theme 4: It helped me include valid evidence and reliable statistics to support my reasons and to choose appropriate vocabulary but my sentence structure did not improve

Theme 5: It help you to know if you are thinking in a correct way about the topic or not

Theme 6: Start providing the Ted Talks from the intensive levels

A content analysis for participants' brainstorming sheets was also done for more concrete evidence. The comparison between participants' word choice before and after the listening process showed a lexical sophisticated development. For example, Extract 1 (see Appendix) was taken from one of the participants' brainstorming sheet of persuasive writing: Has the Arab world become a better place? Words such as technology, communication, economic, education, social, and medication (upper left corner of the paper) were written before the listening part; they reflect general vague concepts. On the other hand, all the other word choice (written after the listening part) is more descriptive and more sophisticated such as poverty, famine, inequality, dictatorship, human flourishing, and homicide.

Moreover, content analysis revealed participants' shift from general and vague ideas to more specific, descriptive, and appealing ones. For example, Extract 2 (see Appendix) was taken from one of the participants' brainstorming sheet of argumentative writing: Should homework be given in the elementary level? The student had a different opinion from the speaker; however, he/she benefited from Ted Talk in constructing a counterclaim with strong evidence based on statistics and experts' opinion such as those written after the listening part about "Clifton B. Parker a Stanford university researcher: too much homework can affect the health- 56\% students found homework primary source of stress" and "Molly Galloway a researcher from Lewis and Clark College who believed that students are forced to do homework instead of playing” (bottom of the brainstorming sheet) .

\section{Conclusion and Recommendation}

Based on the analysis of the results obtained from the questionnaire and focus group, the following conclusions are drawn in the light of the hypotheses of the study: First Hypothesis: Integrating TedTalk videos in the brainstorming stage is motivating for EFL students.

The feedback of the majority of participants showed that they had a positive experience with listening to TedTalks during the brainstorming stage. The videos got them started, especially those who had "blocked mind" or could not rely on their existing knowledge. Hence, it eased the process of generating relevant and mature ideas and also reduced the difficulty level of the prompt. Several participants emphasized the effectiveness of the tool in enhancing their critical thinking and analyzing the prompts from a deep perspective. This is also in line with what Treffinger et al. (2003) emphasized about creativity in writing. They believed that developed content creativity is not only for improving students' writing performance but also for enhancing their thinking skills. Consequently, students were more confident about the ideas they discussed and the descriptive and specific grounds and evidence (facts, statistics, experts' opinion, research findings) they included to serve their claim and add creativity to their persuasive content. Having a motivating and enjoyable experience, students recommended following such an approach in other EFL writing classes. Similarly, Arju (2016) also believed that when students are given better ideas about their writing task, they become more confident and positive about writing.

Second Hypothesis: Ted Talk video is an efficient intervention for helping EFL students show more creativity in the content of their writing and, consequently, improve their writing quality. 
In literature, authors (Styati, 2016; Fleck et al., 2014; Oddone, 2011) reported that videos help EFL writers produce and organize their ideas, select appropriate word choice, and construct correct sentences. Thus, it improves students' writing performance. Similar conclusions were drawn from the quantitative analysis of students' writing. In comparison to the diagnostic test results, students' writing performance improved significantly in the persuasion and argumentation writing. Likewise, the content in terms of fluency and flexibility, originality, and elaboration significantly improved in the two rhetorical modes of writing. Moreover, the content analysis of students' pre and post brainstorming process showed more descriptive and mature ideas in building up their arguments and constructing the counter-claim. This finding aligns with that of Li et al. (2016) who concluded that listening to Ted Talk videos develop students' critical analysis. This is because while listening, students have to distinguish between facts and opinions, judge the validity of evidence, analyze the content, and decide whether they agree with the speaker.

Content analysis also showed a more sophisticated word choice after the listening part. Similar findings were also shared in the focus group interview. Some students mentioned that they benefited from the fluency of the speakers in terms of accurate word choice and correct structure. Hence, as Rababah et al. (2013) found, the integration of ICT tools in EFL classes is invaluable and improves students' EFL writing ability and creativity.

To sum up, integrating Ted Talk videos in the pre-writing stage proved to be an effective approach for the majority of participants in the English Composition and Rhetoric Course (ENGL 210). Questionnaire and focusgroup response analysis reflected students' positive experience with the integration of this type of ICT tool. Hence, it is recommended that teachers in different EFL writing classes adopt this method rather than limit Ted Talk videos only to developing the listening and speaking skills.

Furthermore, for future research, there is a need to conduct a similar study on a larger sample for the sake of generalization. Another contributing future research would be investigating whether Ted Talk videos have an equal impact on the writing of all types of learners: visual, aural, verbal, kinesthetic, logical, social, and solitary.

Finally, initiations such as the Arab reading index project, produced by Mohammed Bin Rashid Al Maktoum Foundation (MBRF) in partnership with the United Nations Development Program/Regional Bureau for Arab States (UNDP/RBAS) are highly needed in the Arab world for igniting the interest of reading in our youth. Such kind of studies aim for promoting a reading culture by studying the rate of the reading practices of Arab citizens and providing the necessary tools for knowledge and development.

\section{Appendix}

\section{Tables and Figures}

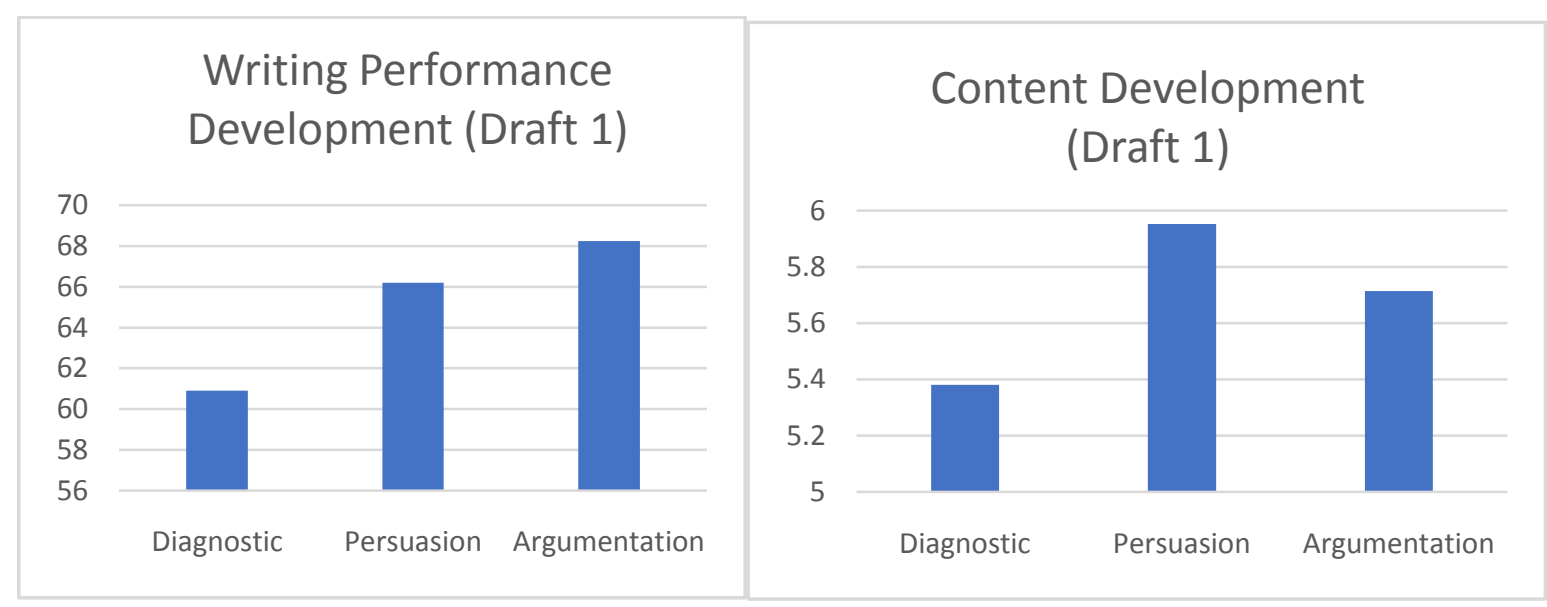

Figure 1: Comparison between the Writing and Content Development 
Table 1: Content/Creativity Criterion Development

Means

Standard Deviation

Means

Standard Deviation
Content Grade Development

\begin{tabular}{|c|c|c|c|}
\hline Diagnostic & Persuasion & Argumentation & Diagnostic \\
\hline 5.3 & 5.9 & 5.7 & 5.3 \\
\hline 0.8 & 0.9 & 0.7 & 0.8 \\
\hline \multicolumn{2}{|c|}{$\begin{array}{c}\text { p-value } \\
\text { 0 }\end{array}$} & \multicolumn{2}{|c|}{$\begin{array}{c}\text { p-value } \\
0\end{array}$} \\
\hline
\end{tabular}

Table 2: Writing Performance Development

Writing Performance Development

\begin{tabular}{|l|l|l|l|}
\hline Diagnostic & Persuasion & Argumentation & Diagnostic \\
\hline 60.9 & 66.1 & 68.2 & 60.9 \\
6.8 & 11.8 & 7.4 & 6.8 \\
\hline \multicolumn{1}{|c|}{$\begin{array}{c}\text { p-value } \\
\text { 0.03 }\end{array}$} & \multicolumn{3}{c|}{$\begin{array}{c}\text { p-value } \\
\text { 0 }\end{array}$} \\
\hline & \multicolumn{3}{|c|}{ p-value } \\
0.2 & \\
\hline
\end{tabular}

Table 3: Triangulation of Questionnaire and Interview Results

\begin{tabular}{|l|l|}
\hline Themes & $\begin{array}{l}\text { Questionnaire results (Strongly Agree) } \\
\mathrm{N}=21\end{array}$ \\
\hline 1. Is an enjoyable approach for brainstorming & $95 \%$ \\
\hline 2.Motivates an interest in writing about the topic raised & $90 \%$ \\
\hline 3. Eases the brainstorming \& outlining process & $95 \%$ \\
\hline 4. Reduces the difficulty level of the prompt & $90 \%$ \\
\hline 5.Helps in improving the quality of writing & $79 \%$ \\
\hline 6. Helps in reflecting more maturity in writing & $90 \%$ \\
\hline 7.Helps in improving word choice & $80 \%$ \\
\hline 5. Increases confidence in writing & $84 \%$ \\
\hline 6.Is recommended for other writing courses & $100 \%$ \\
\hline
\end{tabular}

Extract 1: Persuasive Writing

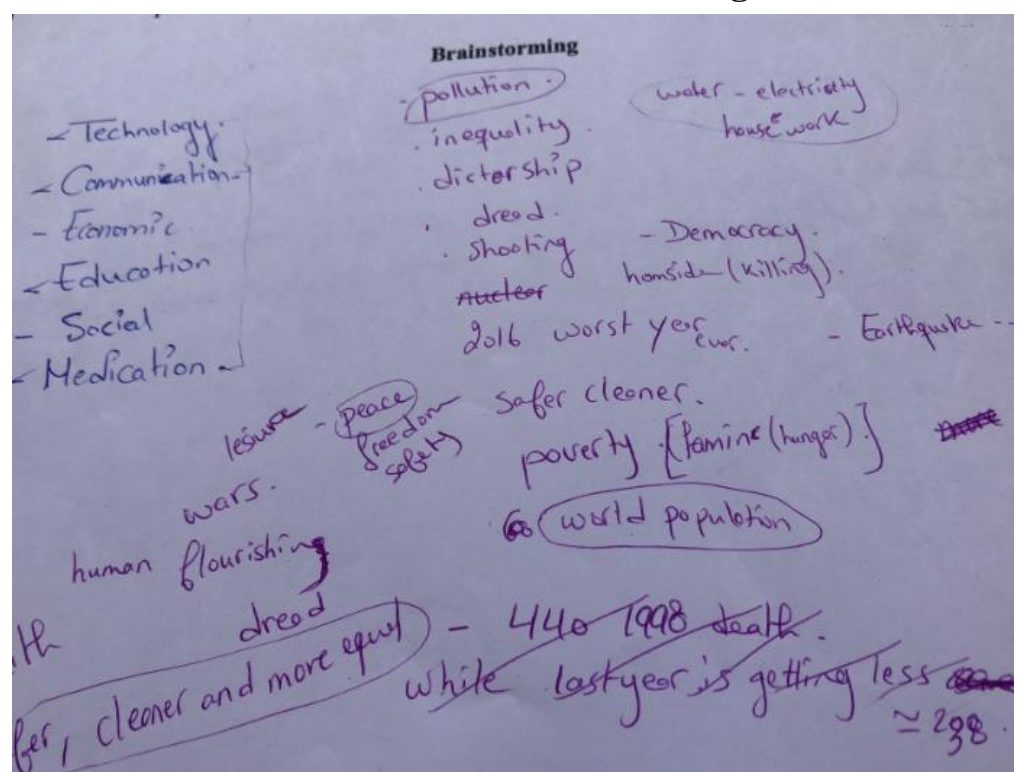

Extract 2: Argumentative Writing 


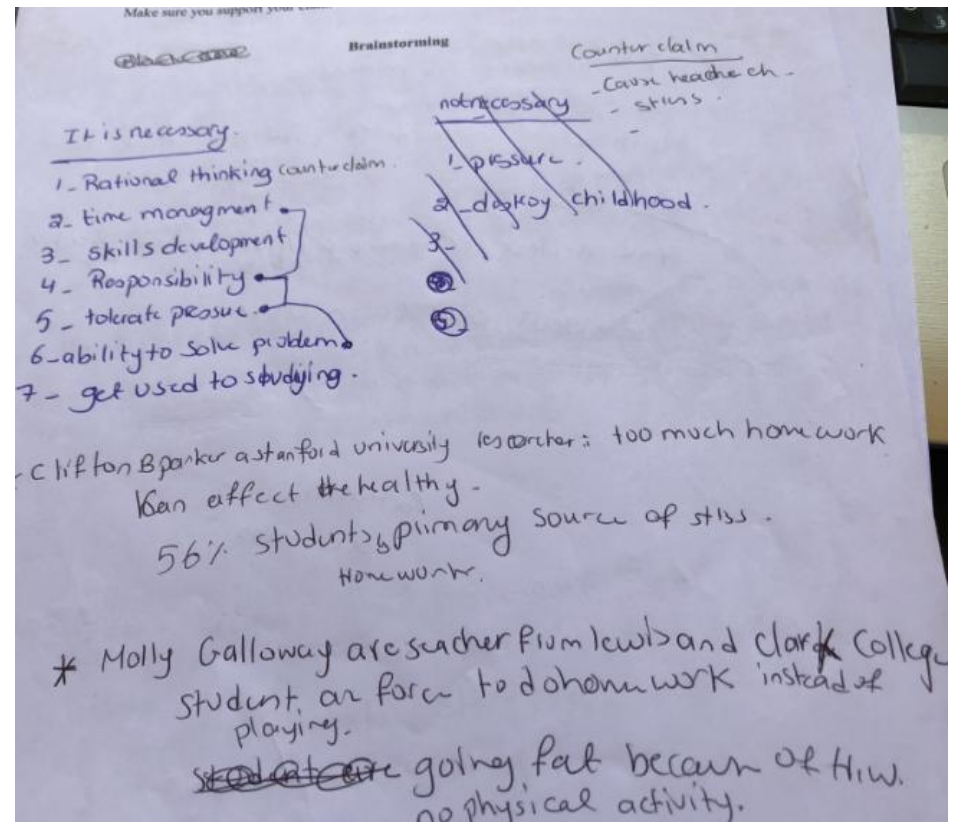

\section{References}

Al-Khatib, B.A. (2012). The effect of using brainstorming strategy in developing creative problem solving skills among female students in Princess Alia University College. American International Journal of Contemporary Research, 2(10).

Allen, L.K., Snow, E. L., Crossley, S. A., Jackson, G. T., \& McNamara, D. S. (2014). Reading comprehension components and their relation to writing. L'annéepsychologique/Topics in Cognitive Psychology, 114, 663-691.

Andrisnsyah, A. (2015). The Effect of Using Mind Mapping in Teaching Recount text to the Students' Writing Abaility at Eighth Grade of SMP 2 Ngadiluwih Academic Year 2015/2016. Published thesis, Universitas Nusantara PGRI Kediri, retrieved on 21st of April, 2016 from: www. simki.unpkediri.ac.id

Al-Oraibi, M. (2016). A new generation of Arabs are changing the status quo. Global Agenda. Retrieved from https://www.weforum.org/agenda/2016/01/how-young-people-can-shape-a-better-future-for-the-arabworld/

Arju, S. (2016). Motivation matters in adopting prewriting strategies and improving writing achievement among Bangladesh adult EFL learners. Asian Journal of Management Sciences \& Education, 5(3), 139- 152.

Bajrami, L., \& Ismaili, M. (2016). The role of video materials in EFL classrooms. Procedia-Social and Behavioral Sciences, 232, 502-506. doi: 10.1016/j.sbspro.2016.10.068

Broadaway, R. (2012). Content-based instruction using Moodle: Teaching with TEDTalks. JALT CALL JOURNAL, 8(3), 211-231.

Creswell, J.W. (2014). Research design: Qualitative, quantitative, and mixed methods approaches $\left(4^{\text {th }}\right.$ Ed.). Washington, DC: Sage.

Dale, L., van der Es, W., \&Tanner, R. (2010). CLIL skills. Harlem: European Platform (Universitet Leiden).

Fleck, B.K.B., Beckman, L.M., Sterns, J.L., \& Hussey, H.D. (2014). YouTube in the classroom: Helpful tips and student perceptions. Journal of Effective Teaching, 14(3), 21-37.

Flick, U. (2014). The Sage Handbook of Qualitative Data Analysis. London: Sage pub.

Godwin-Jones, R. (2007). Emerging technologies. Digital video update:YouTube, Flash, High-Definition. Language Learning and Technology, 11(1), 12-16.

Goldberg, P. D., \& Bush, W. S. (2003). Using metacognitive skills to improve $3^{\text {rd }}$ graders' math problem

solving. Focus on Learning Problems in Mathematics, 25(4), 36-55.

Hashimoto, S., Fukuda, E., \& Okazaki, H. (2015). Improving summarizing skills with TED talks: an account of a teaching lesson using explicit instruction. In F. Helm, L. Bradley, M. Guarda, \& S. Thouësny (Eds), Critical CALL - Proceedings of the 2015 EUROCALL Conference, Padova, Italy (pp. 228-234). Dublin: Research-publishing.net. http://dx.doi.org/10.14705/rpnet.2015.000338 
Ibnian, S.(2010). The effect of using the story- mapping technique on developing tenth grade students' short story writing skills in EFL. English Language Teaching, 3(4), 181-194.

Jameel, A. S., \&Mohamood, D. F. (2017). The effect of flexibility and fluency strategies on developing creative writing skills in English language subject of the fourth preparatory literary students. International Journal of Humanities and Applied Social Science, 2(1), 37-50.

Jeffrey, B., \& Craft, A. (2004). Teaching creatively and teaching for creativity: Distinctions and relationships. Educational Studies, 30(1), 77-87.

Li, Y., Gao, Y., \& Zhang, D. (2016). To speak like a TED speaker- A case study of TED motivated English public speaking study in EFL teaching. Higher Education Studies, 6(1).

Madani, H. (2016). The effects of reading skills on the development of language priority. Case of $1^{\text {st }}$ year EFL students. University of Abou Bakr Belkaid- Tlemeen. Unpublished Ph.D. thesis.

Maghsoudi, M., \&Haririan, J. (2013). The impact of brainstorming strategies Iranian EFL learners' writing skill regarding their social class status. International Journal of language and Linguistics, 1(4-1), 60-67. Doi: 10.11648/j.ijll.s.20130101.20.

Mayora, C. A. (2009). Using YouTube to encourage authentic writing in EFL classrooms. TESL Reporter, 42(1), $1-12$.

Nurlaila, A.P. (2013). The use of mind mapping technique in writing descriptive text. English and Education, $1(2), 9-15$.

Oddone, C. (2011). Using Videos from YouTube and Websites in the CLIL Classroom. Studies about Languages, 18.

Oishi, T. (2015). Applying brainstorming techniques to EFL classroom.NII Electronic Library Service, 121-127.

Rababah, L.M., Bin Mohamed, A. H., Jdaitawi, M.T., \&BaniMelhem, N.Z. (2013). The level of creativity in English writing among Jordanian secondary school students. Arts and Design Studies, 10, 25-29.

Rao, Z. (2007). Training in brainstorming and developing writing skills. ELT Journal, 6 (1), 100-106.

Stewart, D.W., Shamsadani, P.N., \& Rock, D.W. (2007). Introduction: Focus group history, theory, and practice. In Stewart, D.W., Shamdasani, M.N., Rock, D.W. (Eds.). Focus Groups: Theory and Practice (pp.1-27). London: Sage Publications.

Styati, E. W. (2016). Effect of YouTube videos and pictures on EFL students' writing performance. DinamikaIlmu, 16(2), 307-317.

Torrance, E. P. (1974). Torrance Tests of Creative Thinking: Norms-technical manual.Lexington, MA: Ginn.

Torrance, E. P. (1995). Creative motivation scale. Athens: Georgia Studies of Creative Behavior.

Treffinger, D. J., Nassab, C., Schoonover, P., Selby, E., Shepardson, C., Wittig, C., \& Young, G. (2003). Thinking with standards: Preparing for tomorrow (elementary level). Waco, TX: Prufrock Press.

Wu, P., \&Chiou, W. (2008). Postformal thinking and creativity among late adolescents:A post-Piagetian approach. Adolescence, 43(170), 237-252. 